\title{
Process Capability and Average Roughness in Abrasive Water Jet Cutting Process of Stainless Steel
}

\author{
Mohamed Boujelbene \\ College of Engineering of Hail \\ University of Hail \\ Hail, Kingdom of Saudi Arabia \\ mboujelbene@yahoo.fr
}

\begin{abstract}
Process capability analysis is frequently employed to evaluate if a product or a process can meet the customer's requirement. In general, process capability analysis can be represented by using the process capability index. Until now, the process capability index was frequently used for manufacturing processes with quantitative characteristics. However, for a process with qualitative characteristic like cutting surface, the data's type and single specification caused limitations of using the process capability index. Taguchi developed a surface quality by abrasive water jet cutting or quadratic quality loss function to address such issues. In this study, we intend to construct a measurable index which incorporates the process capability index philosophy concept to analyze the process capability with the consideration of the qualitative surface roughness. The manufacturers can employ the proposed index to self-assess the process capability. The objective of this study was to examine the effects of abrasive water jet machining variables like cutting speed of the stainless steel material. The roughness of the varied surface through the cut depth was also measured and determined as a process capability index of 3 zones machined surface.
\end{abstract}

Keywords-abrasive water jet cutting; process capability; cutting speed; surface roughness; stainless steel

\section{INTRODUCTION}

The abrasive water jet (AWJ) cutting technique is one of the most rapidly improving technological methods of cutting materials. In this cutting technique, a thin, high velocity water jet accelerates abrasive particles that are directed through an abrasive water jet nozzle at the material to be cut. AWJ is one of the most widely used technological methods. The advantages of AWJ cutting include the possibility of cutting almost all materials e.g. Titanium, Aluminum, the absence of thermal distortion, high flexibility, small cutting forces and being environmentally friendly. Due to these capacities, this cutting technique is more cost-effective than traditional and non-traditional machining processes [1-9]. The mechanism and rate of material removal during the AWJ cut depends on both the type of abrasive and the range of process parameters. A considerable number of studies have investigated the effects of cutting velocity, spreading distance, water pressure, abrasive grain size and other factors on the surface roughness [6-12]. Thus, it is necessary to have a deeper knowledge of the optimal conditions of operation, which will allow us to ensure a good surface roughness. A large amount of research effort has been made, in recent years, to understand the AWJ process and improve its cutting performance such as the depth of cut and surface finish for various materials [11-12]. Researchers used granite samples for their experimental studies and investigated the effect of process parameters on rock cutting. It was found that entraining of abrasive particles increase the cutting capability of water jets and increases of water jet pressure allow obtaining deeper cut depths. Process capability analysis (PCA) [13-16] is frequently employed by the manufacturers to evaluate if the capability of process can meet the customer's requirement. Process Capability Indices (PCIs) are a quantitative measurement of the process capability in most manufacturing industries. PCIs, such as $\mathrm{Cp}$ and $\mathrm{Cpk}$ are commonly used for most manufactures [15-16], can frequently measure the process capability for the quantitative response for example surface roughness. Authors in [15] evaluate the related scale of the process mean with the tolerance specification (i.e. the difference between the upper tolerance limit and the lower tolerance limit). $\mathrm{Cp}$ evaluates the related scale of the specification's tolerance with process's tolerance. While Cpk simultaneously, evaluates the centering degree and the dispersion degree. These PCIs will make some adjustments if there are necessary particulars like the unilateral specification. For the quantitative type, the theories on PCA and PCIs are well developed in [15-17] but qualitative data type may exist during the manufacturing environment, e.g. the production parts, pistons, gears, the integrated circuit manufacturing, so, the process capability analysis for qualitative data will be an important issue to study. However, most studies only focus on the PCA application for the quantitative response data, and the qualitative response data is seldom mentioned [16-17].

Several difficulties can be mentioned as: (i) the target of the qualitative data may lead to unobvious centering evaluation, e.g. the target will be set as zero defect, (ii) the limitation of the unilateral specification, especially only the upper specification exists, e.g. the defect rate may be less than $1 \%$ and (iii) the quantitative data utilizes the process mean $(\mu)$ and process deviation $(\sigma)$ to compute the PCIs, however, the qualitative data cannot directly utilize them to compute the PCIs. Under the global market environment, to realize the process capability comparison with other competitors can provide helpful 
information for enhancing organizational competence or making strategic decisions. Now, as the concept of concurrent engineering has become widely accepted, design engineers hope to achieve simultaneous product design and process planning, side by side, at an early stage of product development [18-22]. The goals are to shorten the time span required for introducing the new product to the market and to attain the lowest production cost and manufacturing parts with good quality. Hence, what is needed is a way to measure the degree of the producer's process capability, in satisfying the customer's quality requirement. More importantly, a growing number of producers include this measurement value in their purchase contracts with customers, as a documentation requirement [14]. One such measurement is the PCI which is a value which reflects real-time quality status. PCI acts as the reference for real-time monitoring that enables process controllers to acquire a better grasp of the quality of their onsite processes [14, 19-21]. Although PCI is considered as one of the quality measurements employed during on-line quality management, several authors have pointed out that the PCI should be addressed at the beginning of the design stage rather than at the production stage, where PCA is typically done.

The PCI value is typically defined as the ability to carry out a task or to achieve a goal. The controllable factors are the process mean and process variance [16]. The deviation between process mean and design target can be reduced by locating the process mean close to the design target without additional cost being incurred. The process variance can be lowered by tightening the process tolerance, with extra cost incurred. When the conventional on-line PCI is used for PCA during the product and process designs, designer engineers naturally intend to raise the PCI value by locating the process mean near the target value, and by reducing the tolerance value to ensure a better product quality. However, simply increasing the PCI value can easily create additional and unnecessary production costs that result from extra efforts and expensive devices for ensuring tolerance control. Hence, there is a need to balance customer demands for quality and production costs. In this regard, the off-line PCI value is introduced, in consideration of quality loss and production cost. The objective of this study was to examine the effects of AWJ variables such as cutting speed of the stainless steel material on a surface with average roughness $\mathrm{Ra}$. The average roughness of the varied surface through the depth of cut was also measured and expressed as a process capability. Especially, the PCA for different manufacturers will be a significant factor for the collaborators to seek. In this study, we intend to construct a PCI to evaluate the surface roughness machined by the AWJ cutting process. The aim of this study was to examine the effect of cutting speed on surface roughness across the cut surface in AWJ cutting of $316 \mathrm{~L}$ austenitic stainless steel.

\section{MATERIALS AND METHODS}

\section{A. Materials}

The material used in this experimental study has been taken from profile X6CrNiTi18-10. It is strongly allied austenitic stainless steel and its nominal chemical composition is given in Table I. This steel is used in many industrial sectors, like aeronautic, chemical, electrical, navy, nuclear and petroleum. It is also used in various mechanical pieces manufacturing.

\section{B. Experiments Machine Tool}

The experiments were carried out on an NC 3015 EB AWJ cutting system with a KMT Streamline TM system [2] with ultra-high pressure pumps SL-V 50 capable of providing a maximum water pressure of $600 \mathrm{MPa}$ (Figure 1). In this experimental study, there are 6 constant parameters throughout the AWJ Machine (AWJM) process to cut a sheet metal of the stainless steel of $8 \mathrm{~mm}$ depth shown in Table II.

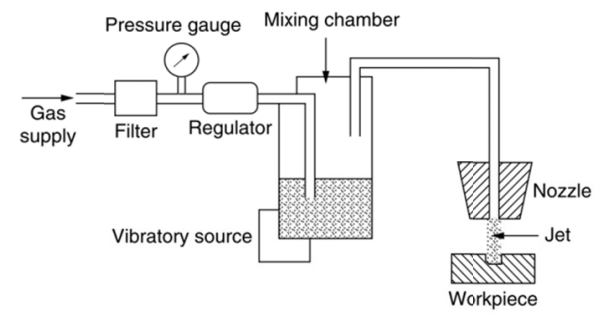

Fig. 1. Experimental AWJ cutting system.

TABLE I. CHEMICAL COMPOSITION IN \% OF THE X6CRNITI18-10

\begin{tabular}{|c|c|c|c|c|c|c|}
\hline $\mathbf{C}$ & $\mathbf{S i}$ & $\mathbf{M n}$ & $\mathbf{P}$ & $\mathbf{S}$ & $\mathbf{C r}$ & $\mathbf{N i}$ \\
\hline 0.06 & 1.00 & 2.00 & 0.045 & 0.015 & 18 & 10 \\
\hline
\end{tabular}

TABLE II. CONSTANT TECHNOLOGICAL PARAMETERS

\begin{tabular}{|c|c|}
\hline Technical Parameters & Value \\
\hline Cutting length & $150 \mathrm{~mm}$ \\
\hline Water pressure & $415 \mathrm{MPa}$ \\
\hline Type of abrasive & Mineral \\
\hline Density of the abrasive & $0.5 \mathrm{~g} / 1$ \\
\hline Abrasive grain size & $80 \mathrm{~g}$ \\
\hline Nozzle diameter & $0,76 \mathrm{~mm}$ \\
\hline
\end{tabular}

\section{Surface Roughness Measurement}

The average surface roughness $(\mathrm{Ra})$ of the workpiece was measured by a Mitutoyo portable surface roughness tester capable of performing measurements in any orientation, including vertical and upside-down, allowing measurements to be performed easily in various situations and setups. The cutoff length and evaluation length were fixed at $0.8 \mathrm{~mm}$ and $4 \mathrm{~mm}$ respectively. The surface roughness was measured in three zones of the machined surface. All measurement values were evaluated. Surface roughness measurements tester is shown in Figure 2.

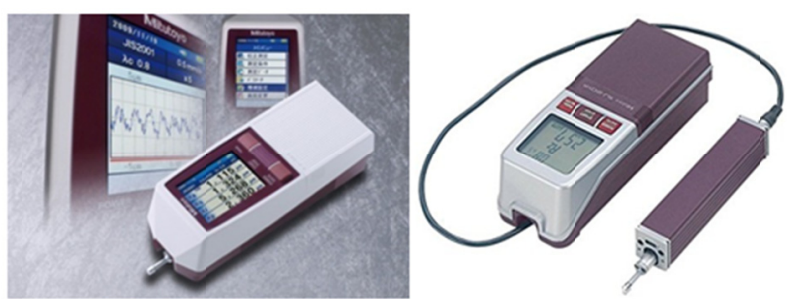

Fig. 2. Experimental surface roughness tester. 


\section{EXPERIMENTAL RESULTS AND DISCUSSION}

\section{A. Surface Roughness of the cut surface}

After machining operations by AWJ cutting process, the cut surface was monitored by optic microscope and is presented in Figure 3 which shows the very good surface cut of the upper edge beginning of the cut (zone 1) and the bad surface machined in the lower edge, ending of the cut (zone 3 ). In this zone there is a presence of the striation marks (Figure 3(b)).

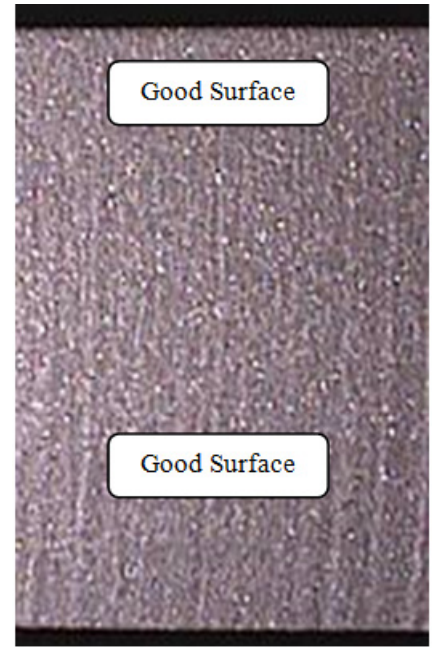

(a)

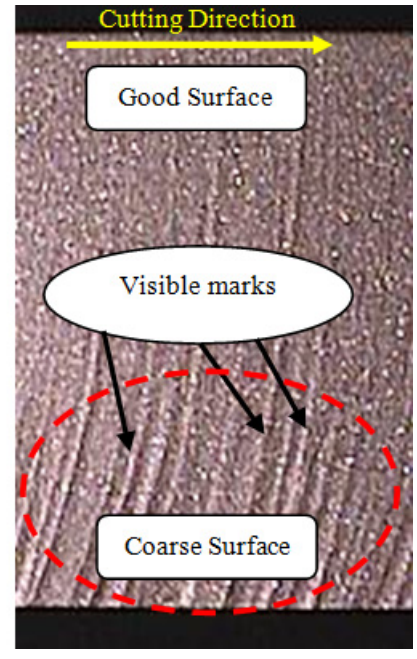

(b)
Fig. 3. Photograph of machined surface after AWJ Cutting (a) Good surface at low cutting speed, (b) Coarse surface at high cutting speed.

Obtained photographs were analyzed and edited with the use of image manipulation software. Cut surfaces were divided in two zones; upper zone (beginning of the cut with no visible presence of machining marks), and lower zone, (ending of the cut with visible machining marks) as shown in Figure 3(b). Lines outlining machining marks and showing their approximate curve angle were added. For the surface cut with the highest cutting speed $\mathrm{V}$ equal to $250 \mathrm{~mm} / \mathrm{min}$, numerous grooves and elevations in the lower zone are clearly visible marks (Figure 3(b)). With decrease in the cutting speed an improvement of surface quality in its lower part can be observed. For the lowest used cutting speed, machining marks are fewer and faintly visible. It can be observed that the width of the zone with visible machining marks and their curve angle increases with the growth in cutting speed. The presence of machining marks in the lower part of cut surfaces is linked to the decrease in kinetic energy of abrasive particles in AWJ.

After machining by AWJ cutting process, with different cutting speeds, we measured the surface average roughness $\mathrm{Ra}$ in three zones (see Figure 4). Table III presents Ra of the all work pieces, in the three zones. It was observed that the sensitivity of measured parameters is directly related to both cutting speed and distance from upper cut edge. With the increase in cutting speed $\mathrm{V}$, a degradation of surface quality defined by analyzed parameters for zone 2 and zone 1 planes was observed (Figures 3 and 5).
Based on the analysis of Table III and Figure 5, it can be stated that the cutting speed $\mathrm{V}$, has a significant influence on the surface roughness of the cut surfaces. Also, the distance from the upper cut surface edge directly affects surface quality and measurement results. In the area where AWJ enters the cut material, decrease in cutting speed by around $20 \%$ (from $\mathrm{V}=250 \mathrm{~mm} / \mathrm{min}$ to $200 \mathrm{~mm} / \mathrm{min}$ ) results in drop of roughness parameter by approximately $14 \%$ in zone 3 . Further decrease of the cutting speed to $150 \mathrm{~mm} / \mathrm{min}$ (decrease by approximately $40 \%$ ) results in surface roughness parameters dropping by $26 \%$ in zone 3.

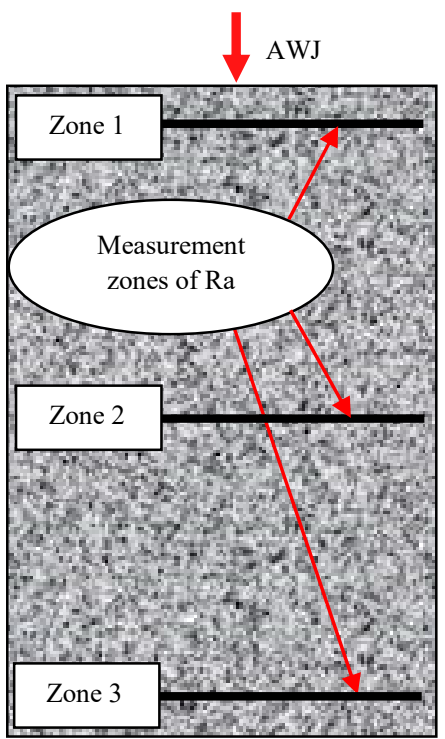

Fig. 4. Measurement zones of Ra of the machined surface.

A downward trend can also be seen when analyzing the measurement results taken in the center of cut surfaces. However, this time the drop is more significant by $20 \%$ for the medium cutting speed and $40 \%$ for the lowest used cutting speed. In the lower part of the studied cut surfaces the sharpest growth in values of measured parameters can be seen for the highest used cutting speed of $250 \mathrm{~mm} / \mathrm{min}$. For the lower cutting speeds, $150 \mathrm{~mm} / \mathrm{min}$, the increase in roughness is not as intense when compared to the values observed for the upper, parts of cut surfaces (zone 1). This can be caused by the drop in the kinetic energy of abrasive water jet being less intense for lower cutting speeds. In this part of the surface, biggest increases in surface quality can be achieved by using the lowest researched cutting speed of $150 \mathrm{~mm} / \mathrm{min}$. Figure 5 shows an excellent surface roughness of the machined surface in the zone 1 , and a bad surface quality in the zone 3, for cutting speed of $250 \mathrm{~mm} / \mathrm{min}$.

\section{PROCESS CAPABILITY}

\section{A. Process Capability}

Process capability $\mathrm{Cp}$ and PCI Cpk are considered shortterm potential capability measures for a process. In Six sigma, we want to describe processes quality in terms of sigma because this gives us an easy way to talk about how capable different processes are by using a common mathematical framework. In other words, it allows us to compare, for 
example, milling processes to turning processes. A good analogy is shooting at a target. If the rounds form a good cluster or grouping in the same spot anywhere on the target you have a high $C p$ value. When you have a tight group of shots landing on the bullseye, you now have a high Cpk.

TABLE III. SURFACE ROUGHNESS AFTER MACHINING BY AWJ CUTTING.

\begin{tabular}{|c|c|c|c|c|}
\hline Exp $\mathbf{N}^{\circ}$ & $\mathbf{V}(\mathbf{m m} / \mathbf{m i n})$ & depth $(\mathbf{m m})$ & & Ra $(\boldsymbol{\mu m})$ \\
\hline 1 & 150 & 8 & Zone 1 & 2.71 \\
\hline 2 & 150 & 8 & Zone 2 & 3.69 \\
\hline 3 & 150 & 8 & Zone 3 & 5.36 \\
\hline 4 & 200 & 8 & Zone 1 & 2.98 \\
\hline 5 & 200 & 8 & Zone 2 & 3.93 \\
\hline 6 & 200 & 8 & Zone 3 & 6.28 \\
\hline 7 & 250 & 8 & Zone 1 & 3.21 \\
\hline 8 & 250 & 8 & Zone 2 & 5.26 \\
\hline 9 & 250 & 8 & Zone 3 & 7.27 \\
\hline \multicolumn{5}{|r|}{} \\
\hline
\end{tabular}

Cpk measures how close you are to your target and how consistent you are around your average performance. A person may be performing with minimum variation, but he can be away from his target towards one of the specification limits, which indicates lower $\mathrm{Cpk}$, whereas $\mathrm{Cp}$ will be high. On the other hand, a person may be on average exactly at the target, but the variation in performance is high (but still lower than the tolerance band (i.e., specification interval, for example \pm 0.15 ). In such case $\mathrm{Cpk}$ will also be lower, but $\mathrm{Cp}$ will be high. $\mathrm{Cpk}$ will be higher only when you're meeting the target consistently with minimum variation [18].

As a quantitative measure, PCIs are widely used to determine whether a process is capable of producing items within customer specification limits. The objective of these statistical measures is to estimate process variability relative to process specifications. Furthermore, a PCI provides a common standard of product quality to suppliers and customers. In classical methods, while normality of the quality characteristics is usually assumed in the estimation process of PCI, in many practical cases, some non-normal distributions occur. For a stable univariate normal process with mean $\mu$ and standard deviation $\sigma$, if we define USL and LSL to be the upper and lower specification limits, respectively, then the process capability $(\mathrm{Cp})$ and the process capability ratio for off-center processes (Cpk), defined in (1) to (4), are the classical measures that are inappropriate for non-normal processes.

$$
\begin{gathered}
C p=\frac{U S L-L S L}{6 \sigma} \\
C p l=\frac{U S L-\mu}{3 \sigma} \\
C p u=\frac{\mu-L S L}{3 \sigma} \\
C p k=\operatorname{Min}\left\{C p u=\frac{\mu-L S L}{3 \sigma}, C p l=\frac{U S L-\mu}{3 \sigma}\right\}
\end{gathered}
$$

In which, one can replace unknown $\mu$ and $\sigma$ by their estimates defined as the sample mean $x$ and sample standard deviation $\mathrm{S}$, respectively. Although various methods are available in the literature to estimate PCI of univariate non normal processes, in many production processes, there are more than one quality characteristics involved. These characteristics are generally correlated, and hence, some multivariate techniques should be employed.

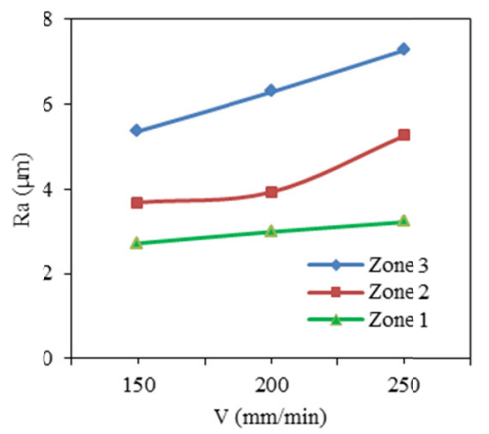

Fig. 5. Surface roughness Ra as funtion of the cutting speed V.

\section{B. Results of the Process Capability}

For analyzing the process capability of the surface roughness $\mathrm{Ra}$, in three zones (zone 1-3) (Ra-z1-3), of the machined surface by AWJ cutting (AWJC). The results of the measure are presented in Table IV and Figures 6-8. The process data of the AWJC process of the stainless steel has lower specification limit LSL $2.8 \mu \mathrm{m}$ and upper specification limit USL $7.2 \mu \mathrm{m}$. The process capability report for $\mathrm{Ra}$ in zone 1, (Ra-z1) of machined surface presented the potential capability $\mathrm{Cp}=6.38$ and $\mathrm{Cpk}=1.74>1.33$ ( $\mathrm{Cpk}$ values of 1.33 or greater are considered to be industry benchmarks), implying we have a very good process in zone 1 (Figure 6). This means that the process is contained within standard deviations of the process specifications. Furthermore, the process capability report for $\mathrm{Ra}$ in zone 2 (Ra-z2) of machined surface presented potential capability $\mathrm{Cp}=5.94$ and $\mathrm{Cpk}=5.24>1.33$, implying that we have an excellent process in zone 2 (Figure 7). These surface roughness values, in zone 1 and zone 2, will produce conforming products as long as they remain in statistical control. The process owner can claim that the customer should experience least difficulty and greater reliability with this product. The process capability report for $\mathrm{Ra}$ in zone 3 (Ra-z3) presented potential capability $\mathrm{Cp}=6.63$ and $\mathrm{Cpk}=-0.20<1.33$, implying that we have a bad or not adequate process in zone 3 (Figure 8). So we have to choose another process for this case.

Figure 8 shows that the process capability deteriorated in zone 3, which indicates the potential risk of an increase in the number of non-conforming parts. It denotes that the process capability is inadequate. For a $\mathrm{Cp}$ different to the $\mathrm{Cpk}$, the process mean is not centered at the process width. The number of non-conforming parts out of the upper specification limit USL is 731642.49 and there is a non value out of the LSL in the observed performance (Figure 8). 
TABLE IV. SURFACE ROUGHNESS RA IN THE 3 ZONES

\begin{tabular}{|c|c|c|c|c|}
\hline Exp $\mathbf{N}^{\circ}$ & $\mathbf{V}(\mathbf{m m} / \mathbf{m i n})$ & $\mathbf{R a - z 1}(\boldsymbol{\mu m})$ & $\mathbf{R a - z 2}(\boldsymbol{\mu m})$ & $\mathbf{R a - z 3}(\boldsymbol{\mu m})$ \\
\hline 1 & 150 & 2.58 & 4.02 & 5.3 \\
\hline 2 & 150 & 2.79 & 3.3 & 5.7 \\
\hline 3 & 150 & 2.81 & 3.78 & 5.0 \\
\hline 4 & 150 & 2.66 & 3.9 & 5.6 \\
\hline 5 & 150 & 2.77 & 3.42 & 5.11 \\
\hline 6 & 150 & 2.63 & 3.74 & 5.46 \\
\hline 1 & 200 & 2.93 & 3.8 & 6.32 \\
\hline 2 & 200 & 2.98 & 3.78 & 6.23 \\
\hline 3 & 200 & 3.13 & 3.99 & 6.14 \\
\hline 4 & 200 & 3.02 & 4.01 & 6.41 \\
\hline 5 & 200 & 2.87 & 4.11 & 6.17 \\
\hline 6 & 200 & 2.94 & 3.89 & 6.39 \\
\hline 1 & 250 & 3.44 & 5.24 & 7.31 \\
\hline 2 & 250 & 3.48 & 5.18 & 7.22 \\
\hline 3 & 250 & 3.33 & 5.46 & 7.14 \\
\hline 4 & 250 & 3.22 & 5.25 & 7.41 \\
\hline 5 & 250 & 3.52 & 5.31 & 7.17 \\
\hline 6 & 250 & 3.41 & 5.12 & 7.34 \\
\hline
\end{tabular}

Process Capability Report for Ra-z1 $(\mu \mathrm{m})$

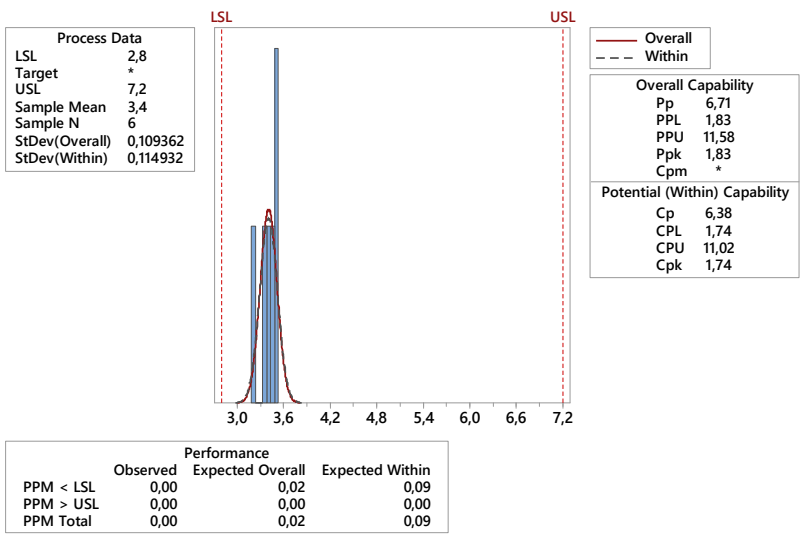

Fig. 6. Process capability report for Ra in zone 1 of the cut surface.

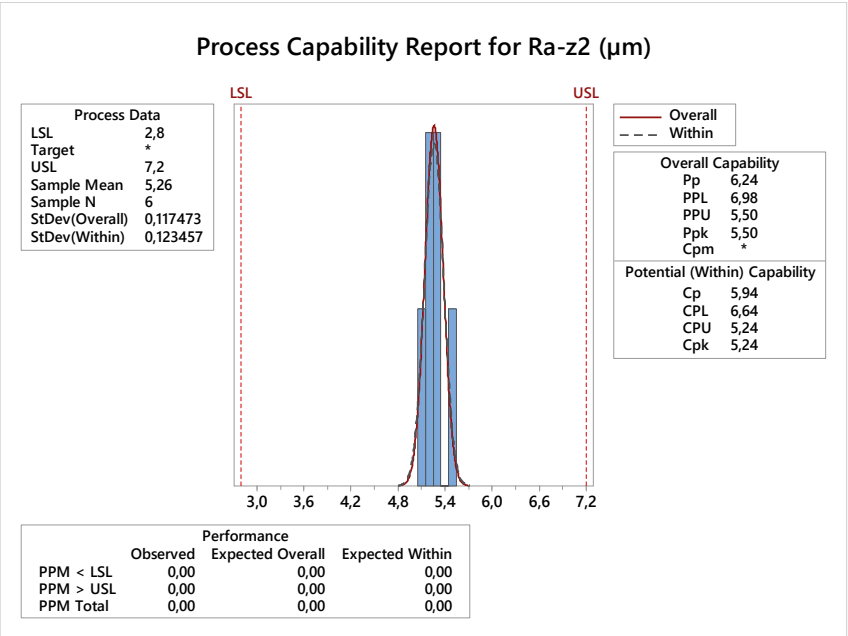

Fig. 7. Process capability report for Ra in zone 2 of the cut surface.
Process Capability Report for Ra-z3 ( $\mu \mathrm{m})$

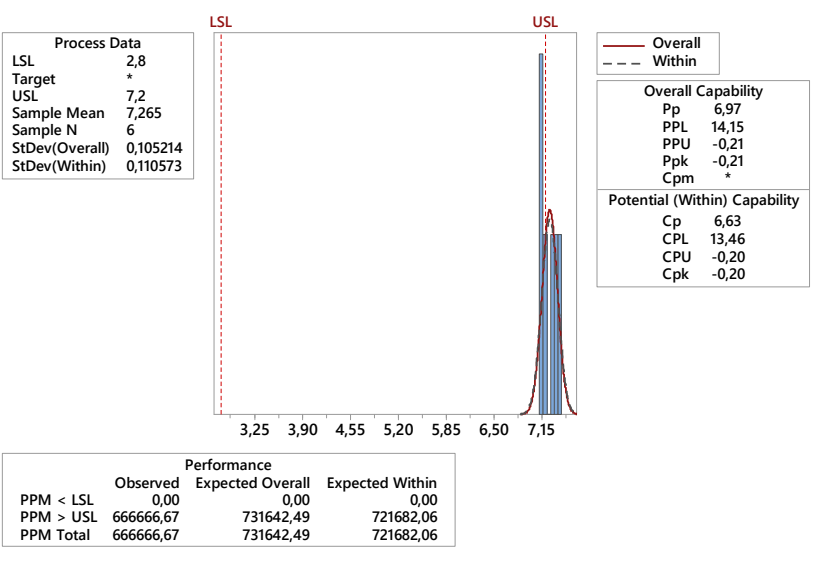

Fig. 8. Process capability report for Ra in zone 3 of the cut surface.

\section{CONCLUSION}

In this study, we constructed a quantitative measurement PCI for the qualitative response of the surface roughness. The quantitative measurements are based on the Taguchi's quality function philosophy and PCI concept. It is a ratio deriving from the customer's quality loss with respect to the actual process's quality loss. By employing the proposed PCI, the manufacturers can assess and meet the customer's requirement. The analysis of the machined surface by AWJC process extracted the following conclusions:

- Edge quality of the cut surface is a function of cutting speed.

- With decrease in cutting speed, cut surface quality visibly improves, which is most clearly noticeable for the lower part of examined cut surfaces. The difference in the measured value of Ra parameter is about $26 \%$ between the highest and lowest researched cutting speeds, in favor of the latter.

- Cut surfaces are characterized by the occurrence of two zones. In the first zone, there are no visible machining marks. In the second one, machining marks can be easily observed. The second zone width and the visibility of machining marks is closely related to the cutting speed.

- Results of this research can have a practical use in determining surface roughness parameters best suited to adequately evaluate cut surfaces of elements machined with the use of AWJ.

- This process will produce conforming products, in zone 1 and zone 2, as long as it remains in statistical control.

- The process capability report for Ra in zone 3, gives a bad or not adequate process in this zone, So, a new process must be chosen.

\section{REFERENCES}

[1] A. Akkurt, "Cut front geometry characterization in cutting applications of brass with abrasive water jet", Journal of Materials Engineering and Performance, Vol. 19, No. 4, pp. 599-606, 2010. 
[2] J. Valicek, S. Hloch, D. Kozak, "Surface geometric parameters proposal for the advanced control of abrasive waterjet technology", The International Journal of Advanced Manufacturing Technology, Vol. 41, pp. 323-328, 2009

[3] A. Daymi, M. Boujelbene, E. Bayraktar, A. Ben Amara, D. Katundi, "Influence of feed rate on surface integrity of titanium alloy in high speed milling”, Advanced Materials Research, Vol. 264-265, pp. 12281233,2011

[4] Y. Wu, S. Zhang, S. Wang, F. Yang, H. Tao, "Method of obtaining accurate jet lag informationin abrasive water-jet machining process", The International Journal of Advanced Manufacturing Technology, Vol. 76, No. 9-12, pp. 1827-1835, 2015

[5] I. Miraoui, M. Boujelbene, E. Bayraktar, "Analysis of cut surface quality of sheet metals obtained by laser machining: thermal effects", Advances in Materials and Processing Technologies, Vol. 1 No. 3-4, pp. 633-642, 2015

[6] M. Boujelbene, A. S. Alghamdi, I. Miraoui, E. Bayraktar, M. Gazbar, "Effects of the laser cutting parameters on the micro-hardness and on the heat affected zone of the mi-hardened steel", International Journal of Advanced and Applied Sciences Vol. 4, No. 5, pp. 19-25, 2017

[7] A. Alberdi, A. Rivero, L. N. Lopez de Lacalle, I. Etxeberria, A. Suarez, "Effect of process parameter on the kerf geometry in abrasive water jet milling", The International Journal of Advanced Manufacturing Technology, Vol. 51, No. 5-8, pp. 467-480, 2010

[8] M. Boujelbene, P. Abellard, E. Bayraktar, S. Torbaty, "Study of the milling strategy on the tool life and the surface quality for knee prostheses ", Journal of Achievements in Materials and Manufacturing Engineering, Vol. 31, No. 2, 610-615, 2008

[9] M. Boujelbene, S. Ezzdini, N. Elboughdiri, W. Ben Salem, W. Youssef, "Investigation on the surface roughness of the high steel material after wire electrical discharge machining process", International Journal of Advanced and Applied Sciences, Vol. 4, No. 5, pp. 130-136, 2017

[10] V. Perzel, P. Hreha, S. Hloch, H. Tozan, J. Valíček, "Vibration emission as a potential source of information for abrasive waterjet quality process control", The International Journal of Advanced Manufacturing Technology, Vol. 61, No. 1-4, pp. 285-294, 2012

[11] M. Palleda, "A study of taper angles and material removal rates of drilled holes in the abrasive water jet machining process", Journal of Materials Processing Technology, Vol. 189, No. 1-3, pp. 292-295, 2007

[12] M. Boujelbene, "Influence of the $\mathrm{CO}_{2}$ laser cutting process parameters on the Quadratic Mean Roughness Rq of the low carbon steel", Procedia Manufacturing, Vol. 20, pp. 259-264, 2018

[13] D. C. Montgomery, Introduction to statistical quality control, 4th edn. Wiley, New York, NY, 2001

[14] K. S. Chen, W. L. Pearn, "An application of non-normal process capability indices", Quality and Reliability Engineering International, Vol. 13, No. 6, pp.355-360, 1997

[15] F. C. Kaminsky, R. A. Dovich, R. J. Burke, "Process capability indices: now and in the future", Quality Engineering, Vol. 10, No. 3, pp. 445453, 1998

[16] L. I. Tong, K. S. Chenn, H. T. Chen, "Statistical testing for assessing the performance of life time index of elcetronic component with exponential distribution”, Int J Qual Reliab Manage, Vol. 19, No. 7, pp. 812-824, 2001

[17] J. P. Chen, C. G. Ding, "A new process capability index for nonnormal distribution", International Journal of Quality and Reliability Management, Vol. 18, No. 7, pp. 762-770, 2001

[18] S. Aravind, K. Shunmugesh, K. T. Akhilc, M. Pramod Kumar, "Process Capability Analysis and Optimization in Turning of $11 \mathrm{sMn} 30$ Alloy", Materials Today: Proceedings, Vol. 4, No. 2, pp. 3608-3617, 2017

[19] P. K. Sahu, S. Pal. "Multi-response optimization of process parameters in friction stir welded AM20 magnesium alloy by Taguchi grey relational analysis", Journal of Magnesium and Alloys, Vol. 3, No. 1, pp. 36-46, 2015

[20] K. Abhishek, S. Datta, S. S. Mahapatra, "Multi-objective optimization in drilling of CFRP (polyester) composites: Application of a fuzzy embedded harmony search (HS) algorithm", Measurement, Vol. 77, pp. 222-239, 2016
[21] A. Jeang, "Optimal process capability analysis for process design", International Journal of Production Research, Vol. 48, No. 4, pp. 957989, 2009

[22] B. El Aoud, M. Boujelbene, E. Bayraktar, S. Ben Salem, I. Miskioglu, "Studying Effect of $\mathrm{CO}_{2}$ Laser Cutting Parameters of Titanium Alloy on Heat Affected Zone and Kerf Width Using the Taguchi Method", Mechanics of Composite and Multi-functional Materials, Vol. 6, pp. $143-150,2018$ 